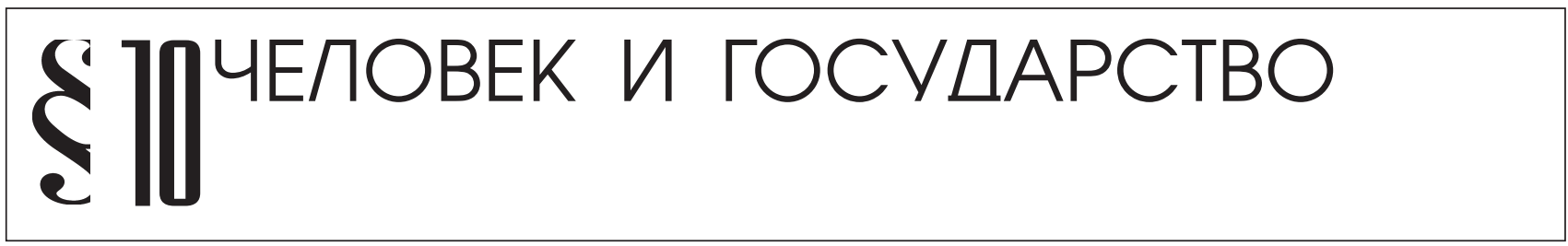

Байматов П.Н.

\title{
КОНСТИТУЦИОННОЕ ПРАВО НА СОЦИАЛЬНОЕ ОБЕСПЕЧЕНИЕ: МЕСТО И РОЛЬ В СИСТЕМЕ ОСНОВНЫХ ПРАВ И СВОБОД ЧЕЛОВЕКА И ГРАЖДАНИНА
}

\begin{abstract}
Аннотация: В Конституции Российской Федерации $n .1$ ст.7 сформулировано положение гласящее, что Российская Федерация является соииальным государством. Основной элемент соииального государства составляет система сочиальных прав, ключевую роль в которой играет право на соииальное обеспечение. Предметом исследования настоящей статьи является конституционная система социальных прав, их классификация и характерные черты. Показана проблематика места и роли соииальных прав, в том числе права на соџиальное обеспечение среди основных, закрепленных Конституиией Российской Федерации прав человека игражданина. Особое внимание уделено выявлению функиий сочиальных прав, в частности функиий права на сочиальное обеспечение. Указанные вопросы исследуются с помощью логического и системного методов, анализа и синтеза, формально-юридического, сравнительно-правового и структурно функиионального методов познания. В статье выдвигается и обосновывается тезис о том, что конституционное право на социальное обеспечение представляет собой основное центральное явление среди социальных прав, поскольку обладает определенными чертами, придающими основополагающий и системообразующийхарактер всем соииальным правам. На основе проведённого исследования сделан вывод об особой роли социальных прав, в том числе права на сочиальное обеспечение, придающих соииальный характер политике российского государства.
\end{abstract}

Abstract: Clause 1, Article 7 of the Constitution of the Russian Federation declares that the Russian Federation is a sociall welfare state. The main element of the welfare state is a system of social rights, of which the key is the right to social security. This article focuses on the constitutional framework of social rights, their classification and characteristics. It shows the problems involved with the place and role of social rights, including the right to social security, being one of the main rights of the man and the citizen enshrined in the Constitution of the Russian Federation. Particular attention is paid to the functions of social rights, in particular the functions of the right to social security. These issues are investigated using logical and systematic methods of analysis and synthesis, technical research and legal comparison, as well as structuralfunctional research. This article extends and substantiates the thesis that the constitutional right to social security is the key legal phenomenon among social rights, since it has certain traits that give it a fundamental, systematically important character among all the social rights. The research leads to a conclusion as to the special role of social rights, including the right to social security, which provide the welfare characteristic to the policy of the Russian state.

Ключевые слова: сочиально-экономические права, концепџия, соџиальная защита, задачи, демография, соииальное государство, материальные блага, признаки, социальное обеспечение, Конституция

Keywords: socioeconomic rights, concept, social safety net, problems, demographics, welfare state, material wealth, signs, social security, Constitution

Конституции Российской Федерации п.1 ст.7 сформулировано положение гласящее, что Российская Федерация является социальным государством. Поясняется, что на практике это означает направленность политики государства на создание условий, обеспечивающих достойную жизнь и сво- бодное развитие человека. ${ }^{1}$ Огромное, если не сказать определяющее значение в реализации названой госу-

\footnotetext{
${ }^{1}$ См.: Добрынин Н.М. Конституционно-правовые аспекты бюджетной обеспеченности реализации социальных гарантий граждан в Российской Федерации ипроблема монетизациильгот//Правоиполитика. 2005. №11.С.4.
} 
DOI: 10.7256/1811-9018.2013.11.10037

При цитировании этой статьи сноска на dоі обязательна

\section{Право и политика $11(166) \cdot 2013$}

дарственной политики имеет система закрепленных Конституцией РФ социальных прав человека.

Oсобое место в системе основных конституционных прав человека занимает, как и другие социальные права, право на социальное обеспечение. Конституция Российской Федерации признает право каждого гражданина на социальное обеспечение и одновременно возлагает на государство обязанность создавать все необходимые условия для беспрепятственного осуществления этого права; перечисляет условия, наступление которых является основанием для социального обеспечения.

Статьей 39 Конституции Российской Федерации каждому гарантируется социальное обеспечение по возрасту, в случае болезни, инвалидности, потери кормильца, для воспитания детей и в иных случаях, установленных законом. Государственные пенсии и социальные пособия устанавливаются законом. Поощряются добровольное социальное страхование, создание дополнительных форм социального обеспечения и благотворительность.

С целью уяснения юридической природы права на социальное обеспечение, как основного в системе социальных прав, рассмотрим признаки социальных прав, позволяющих выделить их в самостоятельную группу прав.

В соответствии с содержанием Международных пактов о правах человека (1966) права человека разграничиваются на, во-первых, гражданско-политические, во -вторых, экономические, социальные и права в области культуры. Приведенное разграничение было осуществлено при принятии Пактов по настоянию отдельных государств, возражавших против включения в разрабатываемый документ юридически обязательных положений по обеспечению прав человека в социально-экономической сфере. ${ }^{2}$ Деление прав человека по содержанию подробно обосновывается теорией существования «негативных» или «юридических» прав и свобод, имеющих, как утверждается, абсолютный характер и для реализации которых, государствам необходимо лишь воздержаться от посягательств на свободу личности. Социально-экономические права же, к которым относится и право каждого человека на социальное обеспечение, отнесенные ко второй группе прав и свобод, получивших название «мнимые», «позитивные» или «программные», не абсолютны, осуществляются постепенно и не являются правами

${ }^{2}$ См.: Островский Я.А. ООН и права человека. М.,1968. С. 7885; Мовчан А.П. Права человека и международные отношения. M.,1982. C. 61-64. в отношении государства, так как для их реализации необходима собственная воля государства, т.е. позитивные государственные действия.

С одной стороны, такого рода противопоставление гражданско-политических и социально-экономических прав противоречит постановлениям самих Пактов, согласно которых, все права и свободы человека и гражданина находятся в неразрывном единстве и взаимозависимости. В преамбулах обоих Пактов говорится, что «согласно

Всеобщей декларации прав человека, идеал свободной человеческой личности, пользующейся гражданской и политической свободой и свободой от страха и нужды, может быть осуществлен только, если будут созданы такие условия, при которых каждый может пользоваться своими экономическими, социальными и культурными правами, так же как и своими гражданскими и политическими правами» ${ }^{3}$

Однако, с другой стороны, рассматриваемое разграничение имеет право на существование, поскольку в отличие от гражданско-политических, социально-экономические права должны быть не только закреплены в национальном законодательстве, но и обеспечены материально в зависимости от уровня и на основе, имеющегося промышленного и социально-экономического развития отдельного государства. Отсюда и различия постановлений Пактов относительно процедуры осуществления закрепленных в них прав. Так статья 2 Пакта о гражданских и политических правах провозглашает: «Каждое участвующее в настоящем Пакте государство обязуется уважать и обеспечивать всем находящимся в пределах его территории и под его юрисдикцией лицам права, признаваемые в настоящем Пакте, без какого бы то ни было различия ...», статья же 2 Пакта об экономических, социальных и культурных правах содержит менее императивную норму, а именно: «Каждое участвующее в настоящем Пакте государство обязуется в индивидуальном порядке и в порядке международной помощи и сотрудничества, в частности, в экономической и технической областях, принять в максимальных пределах имеющихся

ресурсов меры к тому, чтобы обеспечить постепенно полное осуществление признаваемых в настоящем Пакте прав всеми надлежащими способами, включая, в частности, принятие законодательных мер» ${ }^{4}$.

3 См.: Международная защита прав и свобод человека: Сборник документов// Сост. Г.М. Мелков. М.,1990. С.20.

4 См.: Международная защита прав и свобод человека: Сборник документов// Сост. Г.М. Мелков. М.,1990. С.33,21. 
Таким образом, мы наблюдаем некоторую противоречивость в определении сущности прав и свобод человека, в том числе и, прежде всего, социальных прав. С одной стороны, указывается на единство и неразрывность, взаимосвязанность всех прав человека, с другой, на их обособленность и возможность реализации лишь в зависимости от определенных условий, в частности наличия ресурсной базы.

Еще одним признаком, который может иметь практическое значение при реализации социальных прав человека, является возможность ограничения на пользование некоторыми правами, предусмотренная в Пактах о правах человека. Например, Пакт об экономических, социальных и культурных правах определяет, что государства-участники могут вводить ограничения на пользование отдельными правами человека, провозглашенными в нем, но только при соблюдении ряда, указанных в Пакте, условий.

Другим признаком, который характеризует правовую природу социальных прав, является их отнесение или не отнесение к «основным правам человека». Прежде всего, необходимо уяснить какие же права входят в перечень основных, какова их сущностная особенность, чем они отличны от иных прав, однако данный вопрос остается открытым уже долгое время. По мнению В.А. Карташкина, перечень основных прав дан во Всеобщей декларации и Пактах о правах человека, но он не является исчерпывающим, так как данную группу необходимо дополнять комплексом прав, принадлежащих народам и нациям. ${ }^{5}$

Предполагается, что к основным необходимо относить права и свободы, провозглашенные в международных соглашениях. Однако данная позиция не согласуется с указанием Пактов о правах человека, согласно которых «никакое ограничение или умаление каких то ни было основных прав человека, признаваемых или существующих в какой-либо стране в силу закона, конвенций, правил или обычаев» ${ }^{6}$, не допускается под тем предлогом, что в Пактах не признаются такие права или что они признаются в меньшем объеме. Иначе говоря, признание прав человека основными осуществляется не только благодаря закреплению в международных соглашениях, но и исходя из фиксации в системе национального законодательства. По смыслу самого термина основными

${ }^{5}$ См.: Карташкин В.А. Гуманитарный компонент всеобъемлющей системы международной безопасности // Советский ежегодник международного права. 1987. М., 1988. С.28.

${ }^{6}$ См.: Международная защита прав и свобод человека: Сборник документов// Сост. Г.М. Мелков. М., 1990. С.22,35 должны признаваться такие фундаментальные права, которые столь присущи человеку, что их соблюдение обязательно для каждого государства независимо от того, является ли оно участником соответствующих соглашений или нет. Представляется, что деление на основные и неосновные, т.е. производные права и свободы является весьма условным. На наш взгляд такое деление вообще противоречит духу, сути понимания прав и свобод человека как неотъемлемых свойств личности, вытекающих из самой природы и социальных условий ее осуществления.

Еще один сущностный признак, позволяющий определиться с местом и ролью социальных прав, в том числе права на социальное обеспечение-это отнесение указанных прав к правам «второго поколения».

Если в конце XVIII века все провозглашаемые и законодательно закрепляемые права, относящиеся к категории «естественных и неотчуждаемых» концентрировались вокруг идеи свободы, как высшей ценности, то в XX веке появились права «второго поколения», призванные гарантировать жизнь не только свободную, но и достойную. Права второго поколения, т.е. социально-экономические, откорректировали правовую модель отношений личности и государства. Если гражданские и политические права были призваны оградить личность от произвольных действий властей, «поместив» ее в охраняемое законом «пространство свободы», то социально-экономические права определенным образом «привязывали» человека к государству, обязывая последнее помогать тем, кому грозит опасность утонуть «в море свободы». Но эту помощь государство могло оказывать лишь за счет тех членов общества, которые оказались наиболее искусными пловцами. При этом некоторыми учеными права второго поколения рассматриваются как «немалая угроза свободе». Социально-экономические права сдерживают социальную активность и экономическую предприимчивость граждан, поскольку предполагают произвольное (без эквивалентного возмещения) изъятие дохода (собственности) у наиболее успешных членов общества. Их наиболее полная реализация «приучает ... аутсайдеров к социальному иждивенчеству». ${ }^{7}$

Таким образом, если суть гражданских и политических прав состоит в ограничении роли государства в духовном, социально-экономическом и политическом регулировании, предоставляя больше свободы выбора

\footnotetext{
${ }^{7}$ См.: Елисеев Б. П. Трансформация концепции социальных прав в Российской Федерации: обеспечение экономической реформы и соблюдение конституционно закрепленных социальных прав // Юрист. 2004. №12. С. 7.
} 
DOI: $10.7256 / 1811-9018.2013 .11 .10037$

При цитировании этой статьи сноска на доі обязательна

\section{Право и политика $11(166) \cdot 2013$}

для личности, то социально-экономические права расширяют сферу государственного контроля, повышают патерналистскую роль государства по отношению к своим гражданам ${ }^{8}$. Права первого поколения воплотили ценности либерального общества. Права второго поколения-отражают ценности социального государства.

Вот те, на наш взгляд, наиболее отличительные признаки социальных прав, которыми в полной мере обладает и право на социальное обеспечение, характеризующие рассматриваемые права как самостоятельную группу конституционных прав человека и гражданина и определяющие их роль и место среди основных прав человека.

Рассматривая вопрос деления прав человека на группы, необходимо отметить, что возможность выделения в рамках всей совокупности прав человека отдельных групп не противоречит тезису о неделимом характере всех человеческих прав. Оба Пакта о правах человека указывают на взаимозависимость и неразрывное единство всех прав человека. Права и основные свободы человека неделимы, полное осуществление гражданских и политических прав невозможно без осуществления экономических, социальных и культурных прав ${ }^{9}$. Для более полного определения места и роли социальных прав, в том числе права на социальное обеспечение обратимся к собственно понятию социальных прав. В современном понимании права человека - это неотъемлемые свойства, наиболее существенные возможности развития, которые определяют меру его свободы. Социальные права человека - это права, закрепленные в нормах международного и внутригосударственного права, которые реализуются в социальной сфере, гарантируют достаточный уровень жизни, отражают статус различных социальных групп, обеспечивают социальную свободу и социальную безопасность каждой личности, активную роль в осуществлении которых играет государство. Экономические, социальные и культурные права образуют составную часть системы неотъемлемых прав человека, это - фундаментальные нормы, без соблюдения которых в современном обществе нельзя обеспечить социальный прогресс и улучшение условий жизни, осуществить «идеал свободной человеческой личности», гарантировать достоинство, всем членам

\footnotetext{
${ }^{8}$ См.: Михайловская И. Б. Концепция прав человека и их значение для посткоммунистической России // Российский бюллетень по правам человека. 1997. № 9.С.2.

${ }^{9}$ См.: Бахин С. В. О классификации прав человека, провозглашенных в международных соглашениях // Правоведение. 1991. №2.C.50.
}

человеческой семьи, основы свободы, справедливости и мира. Эти права охватывают нормы, касающиеся положения человека в сфере труда и быта, занятости, благосостояния, социальной защищенности и имеющие целью создание условий, при которых люди могут быть «свободны от страха и нужды» ${ }^{10}$. Как видно из вышеперечисленного, три вида прав человека-социальные, экономические и культурные - тесно связаны между собой, однако каждая из этих групп имеет свои границы, определяемые сферой жизнедеятельности человека. Исходя из этого, социальные права определяются, как совокупность конституционных прав человека, дающих ему возможность претендовать на получение от государства материальных благ. ${ }^{11} \mathrm{~K}$ конституционным социальным правам человека и гражданина, справочник под редакцией В.И.Лафитского относит: право на социальное обеспечение, право на образование, право на охрану здоровья и медицинскую помощь, право на жилище, особые права детей и права инвалидов. ${ }^{12}$ А.Н. Соколов отмечает, что социальные права и свободы обеспечивают человеку достойный уровень жизни и социальную защищенность и относит к ним: право на равную оплату за равный труд, без какой-либо дискриминации; право на условия работы, отвечающие требованиям безопасности жизни; право на справедливое и удовлетворительное вознаграждение, обеспечивающее достойное человека существование для него самого и его семьи и дополняемое при необходимости другими средствами социального обеспечения; право на защиту от безработицы; право на жилище; право на создание профессиональных союзов и вхождение в них для защиты своих интересов; право на отдых и досуг, в том числе право на разумное ограничение рабочего дня и на оплачиваемый периодический отпуск; право на такой жизненный уровень ,включая пищу, одежду, жилище, медицинский уход и необходимое социальное обслуживание, который требуется для поддержания здоровья и благосостояния самого человека и его семьи; право на обеспечение на случай безработицы, болезни, инвалидности, вдовства, наступления старости или иного случая утраты средств к существованию по независящим от индивида обстоятельствам; право на материнство и

\footnotetext{
${ }^{10}$ См.: Гордон Л.А. Социально-экономические права человека: содержание, особенности, значение для России// Общественные науки и современность.М.,1997. С.6.

${ }^{11}$ См.: Конституционное (государственное) право: Справочник/ Под ред. В.И. Лафитского. М.,1995. С. 153.

${ }^{12}$ См.: Конституционное (государственное) право: Справочник/ Под ред. В.И. Лафитского. М.,1995. С. 154.
} 
DOI: 10.7256/1811-9018.2013.11.10037

При цитировании этой статьи сноска на dоі обязательна

Человек и государство

детство; право на наивысший, достижимый уровень физического и психического здоровья. ${ }^{13}$

Критерием выделения социальных прав в самостоятельную группу конституционных прав, по мнению А.Ф. Малого, служит «возможность получения социальной помощи со стороны государства». ${ }^{14}$ Исходя их этого, к социальным правам автор относит право на безопасный труд, право на равно вознаграждение за труд не ниже минимального размера оплаты труда, право на отдых, право на защиту от безработицы, право на защиту материнства, детства, семьи, право на социальное обеспечение. В.А.Иваненко и В.С. Иваненко определяют социальные права, как согласованные и признанные мировым сообществом в целом, закрепленные в законодательстве большинства современных государств минимальные правовые нормы-стандарты прав человека в социальной сфере, предусматривающие такие условия жизни, которые позволяют каждому свободно поддерживать и развивать свою человеческую природу ${ }^{15}$.

Анализируя изложенные мнения ученых, представленные ими понятия и наполнение содержанием группы социальных прав, необходимо отметить тот бесспорный факт, что во всех определениях, как мы видим, центральное место занимает, на взгляд автора, право на социальное обеспечение. По мнению автора, именно право на социальное обеспечение является приоритетным, придающим всем социальным правам их сущностную характеристику, отличающую данную группу прав от иных прав, позиционирующим все социальные права как права, нацеленные на обеспечение достойного существования человека.

Право на социальное обеспечение является центральным, занимая ведущую роль в системе социальных прав человека. Указанный тезис подтверждается той ролью и значением права на социальное обеспечение, которое оно занимает в жизни современного общества. В свою очередь, значение и место, а также содержательное наполнение права определяют прежде всего запросы текущего состояния общества, существующие проблемы на том или ином историческом этапе развития общества и государства. Современная демографическая ситуация требует правового воздействия на процессы, происходящие в обществе, а без выражен-

${ }^{13}$ См.: Россия на рубеже веков; укрепление государственности/ Под ред. А.Н. Соколова. Калининград, 2001. С.259.

${ }^{14}$ См.: Мальй А.Ф. Конституционное право РФ: Учеб. пособ. в схемах. Саранск, 1996. С.50.

${ }^{15}$ См.: Иваненко В.А. ,Иваненко В.С. Социальные права человека и социальные обязанности государства: международные и конституционные правовые аспекты.СПб.,2003. С.39. ной в праве государственной воли демографическую проблему не решить. Воздействие права социального обеспечения на демографические процессы - общепризнанный факт. Однако, несмотря на исследования значения и влияния права социального обеспечения на демографию в учебной и научной литературе ${ }^{16}$, потенциал этого права в решении демографической проблемы до настоящего времени не используется в полной мере.

Важнейшим демографическим феноменом на рубеже XX-XXI веков явилось глобальное увеличение продолжительности жизни населения и, как следствие, рост доли пожилых людей в общей популяции населения стран всего мира. Темп прироста пожилого населения значительно опережает темп прироста всего населения. При этом, чем старше возрастная группа, тем интенсивнее растет ее численность. Резкое постарение населения является важнейшей социальной проблемой, которая оказывает значительное влияние на экономические, производственные и общественные отношения современного мира. Наряду с процессом демографического старения, существует проблема увеличения инвалидов среди всех возрастных групп, населения, в том числе молодежи. Население Российской Федерации на 01.01.2012 года составило 143,056 миллиона, из них старше трудоспособного возраста 32,433 млн. человек. К 2010 году численность граждан старшего поколения увеличилась по сравнению с 2004 годом почти на 1 млн. человек, к 2015 году увеличится на 3,1 млн. человек. Структура населения по возрасту существенно меняется, доля лиц старших возрастов (мужчины старше 60 лет, женщины- 55 лет) увеличилась к 2010 году до $21,9 \%$, к 2015 году она возрастет до $24,5 \%$. При этом в некоторых субъектах Российской Федерации доля пожилых уже сейчас превышает $25 \%$ и доходит до $28 \%{ }^{17}$. В Тюменской области, в качестве примера, если говорить в абсолютных цифрах статистика выглядит следующим образом: на 01.01.2012 численность населения всего составила 3459400 человек из них старше трудоспособного возраста 480,8 тыс. человек, инвалидов свыше 100 тыс. человек. Исходя из представленных цифр, уже можно сделать вывод о важности реализации и функционального значения регулирующей роли права на социальное обеспечение отдельных категорий

\footnotetext{
${ }^{16}$ См.: Захаров М.Л., Тучкова Э.Г. Право социального обеспечения России: Учебник. 3-е изд. М., 2004. С. 39; Право социального обеспечения России: Учебник / Под ред. К.Н. Гусова. 3-е изд. М., 2006. C. 12.

${ }^{17}$ В.Н. Крутько, Т.М.Смирнова. Человеческий капитал: проблема и ресурс инновационного развития России. М., 2012.
} 
DOI: $10.7256 / 1811-9018.2013 .11 .10037$

При цитировании этой статьи сноска на доі обязательна

\section{Право и политика $11(166) \cdot 2013$}

граждан пожилого возраста, инвалидов и других незащищенных категорий населения (многодетные семьи, одинокие родители и др.) как необходимого элемента в позитивном развитии демографической ситуации в Российской Федерации..

Другой, весьма актуальной, основной проблемой развития Российской Федерации остаются низкий уровень жизни и сильная дифференциация доходов, что приводит к резкому социальному расслоению и возможным социальным потрясениям. В этой связи задачей демографической политики, а значит и социального обеспечения, становится сокращение масштабов бедности и неравенства. В условиях рыночной экономики у государства есть два способа воздействия на уровень жизни населения: 1) регулирование доходов, 2) система социальной защиты. Обеспечение высокого дохода от занятости в виде оплаты труда, в условиях отсутствия у государства прямых рычагов воздействия на хозяйствующие субъекты, является трудновыполнимой задачей государственных институтов. В такой ситуации, государство имеет возможность использования инструментов социального обеспечения. Социальное обеспечение является эффективным механизмом противодействия неравенству, поскольку выступает способом перераспределения внутреннего валового продукта путем предоставления гражданам материальных благ в целях выравнивания их личных доходов при наступлении социальных рисков для поддержания их полноценного социального статуса. ${ }^{18}$ Решение данной задачи, способствующее ослаблению социальной напряженности в обществе, порождаемой чрезмерными различиями в уровне жизни различных слоев населения необходимо определять как решение задачи политической. Довольно успешно названная политическая задача была решена инструментами права социального обеспечения в период кризисных явлений в экономике Российской Федерации в период 2009-2011 годов. Так на территории Тюменской области с 2009 года в рамках реализации Программы по содействию занятости населения и снижению напряженности на рынке труда, утвержденной распоряжением Правительства Тюменской области от 13.01.2009 N 1-рп была установлена и действовала до 2011 года дополнительная мера социальной поддержки в форме единовременной выплаты в целях содействия развитию малого предпринимательства и самозанятости, предоставляемая безработным гражданам. За все время реализации указанной программы адресную помощь получили свыше

${ }^{18}$ См.: Захаров М.Л., Тучкова Э.Г. Право социального обеспечения России: Учебник. 3-е изд. М., 2004. С. 39.
2 тыс. человек, что позволило сохранить гражданам свой социальный статус, и в конечном итоге реализовать свое право на достойную жизнь.

Одним из социальных рисков, является бедность. Для 55 - 60\% населения России малообеспеченность - главная жизненная проблема. Основные причины бедствования многих наших сограждан заключаются в обесценении их труда, а также в безнравственно низком и социально опасном размере пенсий ${ }^{19}$. Поэтому институт государственной социальной помощи получает все большее развитие в системе права социального обеспечения. Т.В. Деркачева отмечает, что «государственная социальная помощь имеет все признаки самостоятельной организационно-правовой формы социального обеспечения. Во-первых, она распространяется на особых субъектов - малоимущие семьи и малоимущих одиноко проживающих граждан. Во-вторых, источниками финансирования служат бюджеты различных уровней. В-третьих, в рамках государственной социальной помощи предоставляются особые виды социальных выплат и услуг. В-четвертых, государственная социальная помощь назначается решением органа социальной защиты населения по месту жительства или месту пребывания малоимущего субъекта» ${ }^{20}$. В контексте демографического развития России значение института государственной социальной помощи состоит в предоставлении средств к существованию малообеспеченным гражданам, что позволяет им удовлетворять жизненно важные потребности, тем самым воздействуя на продолжительность жизни. В контексте решения политической задачи стабильности развития общества, указанный институт права на социальное обеспечение выполняет роль амортизатора негативных отношений в обществе, нивелируя резкий социальный разрыв, материальное неравенство граждан.

Таким образом, важность представленных задач для стабильного развития общества, в решении которых значительную роль играют институты права на социальное обеспечение, позволяет сделать вывод об основном характере, центральном месте данного права в системе социальных прав человека и гражданина. Ценность социальных прав, в том числе конституционного права на социальное обеспечение, определена еще и тем, что важнейшей целью конституционного правосудия, провозглашается защита социальных

\footnotetext{
${ }^{19}$ См.: Беляева Л.А. Материальное неравенство в России. Реальность и тенденции // Социологические исследования. 2007. N 11. С. 34.

${ }^{20}$ См.: Деркачева Т.В. Правовое регулирование государственной социальной помощи (федеральный и региональный аспекты): Дис. ... канд. юрид. наук. М., 2002. С. $156-157$.
} 
DOI: $10.7256 / 1811-9018.2013 .11 .10037$

При цитировании этой статьи сноска на dоі обязательна

Человек и государство

прав человека и гражданина, поскольку в своей основе они содержит принцип обеспечения справедливости. Снижение социальной диспропорции, преодоление несправедливости - это задача действительно общая для всех ветвей государственной власти: исполнительной, законодательной, судебной и, в том числе, для конституционного правосудия, разумеется, присущими ему инструментами судебной защиты социальных прав.

Рассматривая институт конституционных социальных прав необходимо констатировать следующее. На сегодняшний день не существует единой концепции осуществления социальных прав, равно как не существует и единой их классификации на основе характера выполняемой социальной роли. Некоторые ученые полагают, что социальные права - это лишь те права, которые непосредственно связаны с реализацией социальной защиты, а именно: охрана семьи, материнства и детства, право на социальное обеспечение, право на жилище, право на охрану здоровья и медицинскую помощь, право на благоприятную окружающую среду (статьи 38, 39, 41 и 42 Конституции) $)^{21}$. Определенные трудности в понимании природы социальных прав, разночтения в предлагаемых перечнях этих прав (в том числе в тех, которые закрепляются официально в конституциях, международно-правовых документах), а также проблемы выработки механизмов и гарантий их реализации, контроля за деятельностью органов государства по их соблюдению, - все это связано прежде всего с определенной разноплановостью их правовой природы и содержания, а также с тем, что эти права сравнительно недавно стали признаваться в качестве основных прав человека.

Так до недавнего времени доминировала западная - классическая либеральная- концепция понимания социальных прав согласно которой, социальные права не рассматривались как права в собственно юридическом смысле. Они рассматривались как притязания индивида на получение от государства определенных материальных благ гарантирующих «достойный уровень жизни». ${ }^{22}$ Каас Санстей говорит об опасностях конституционализации социальных прав. По его мнению, придание социальным правам конституционного

\footnotetext{
${ }^{21}$ См.: Доклад Председателя Конституционного Суда Российской Федерации В.Д. Зорькина «Защита социальных прав и преодоление несправедливости: Проблемы конституционного правосудия». // http://www.ksrf.ru/ News/ Speech/ Pages/

${ }^{22}$ См.: Елисеев Б. П. Трансформация концепции социальных прав в Российской Федерации: обеспечение экономической реформы и соблюдение конституционно закрепленных социальных прав // Юрист. 2004. №12. С. 7.
}

статуса для стран с переходной экономикой может нанести ущерб праву частной собственности и самому экономическому развитию. Конституционализация социальных прав обрекает бедные страны либо на стагнацию, либо на бесцеремонное пренебрежение конституционными нормами. ${ }^{23}$

Тем не менее, в юридической науке и судебной практике нарастает тенденция рассматривать закрепленные Конституцией социальные права не только как принципиальные ориентиры для законодателя, но именно как основные права, равные по значимости конституционным гражданским и политическим правам.

Конституционное право на социальное обеспечение - наряду с гражданскими и политическими правами - по своей природе относится к фундаментальным правам человека, неотчуждаемым и принадлежащим каждому от рождения. Основанное на принципах справедливости и социальной солидарности, оно закреплено Конституцией в качестве непосредственно действующего и подлежит судебной защите. Как таковое, оно наряду с иными социальными правами, обязывают законодательную и исполнительную власть, создают ориентиры для проведения социальной политики государства, формируют и осуществляют реализацию программной установки, закрепленной в Конституции Российской Федерации о социальном характере российского государства.

Закрепленные в Конституции Российской Федерации 1993 г. социальные права человека и гражданина, однако нельзя рассматривать лишь как рекомендации для государственной социальной политики. Соответствующие конституционные нормы имеют ту же юридическую силу, что и остальные конституционные нормы. Квинтэссенцией социальных прав человека и гражданина, наиболее ярко характеризующей их суть и основу, необходимо признать право на социальное обеспечение, поскольку в основе и центре его находится человек, который в силу определенных жизненных обстоятельств нуждается в помощи государства. Социальные права человека и гражданина, установленные в Конституции Российской Федерации 1993 г., следует рассматривать как права прямого действия, обеспечивающие человеку достойный уровень жизни и социальную защищенность от негативного воздействия рынка, ограничивающие и минимизирующие отрицательные последствия экономической политики государств, причем обеспечение их должно

\footnotetext{
${ }^{23}$ См.: Сайнстейн К.P. Против позитивных прав// Российский бюллетень по правам человека.1995. №6. С.19.
} 


\section{Право и политика 11 (166) • 2013}

осуществляться в той мере, в какой это требуется для поддержания социального мира и не вести к чрезмерному ограничению классических личных и политических прав и свобод.

\section{Библиография:}

1. Абрамов А.И. Понятие функции права // Журнал российского права. 2006. N 2. С. 80.

2. Абрамов А.И. Теоретические и практические проблемы реализации функций права. Самара, 2008. C. 43 .

3. Бахин С. В. О классификации прав человека, провозглашенных в международных соглашениях // Правоведение. 1991. №2.С.50.

4. Беляева Л.А. Материальное неравенство в России. Реальность и тенденции // Социологические исследования. 2007. N 11. С. 34.

5. Гордон Л.А. Социально-экономические права человека: содержание, особенности, значение для России// Общественные науки и современность.М.,1997. С.6.

6. Деркачева Т.В. Правовое регулирование государственной социальной помощи (федеральный и региональный аспекты): Дис. ... канд. юрид. наук. М., 2002. С. 156-157.

7. Добрынин Н.М. Конституционно-правовые аспекты бюджетной обеспеченности реализации социальных гарантий граждан в Российской Федерации и проблема монетизации льгот // Право и политика. 2005. №11. C.4.

8. Елисеев Б. П. Трансформация концепции социальных прав в Российской Федерации: обеспечение экономической реформы и соблюдение конституционно закрепленных социальных прав // Юрист. 2004. №12. С. 7.

9. Захаров М.Л., Тучкова Э.Г. Право социального обеспечения России: Учебник. 3-е изд. М., 2004. С. 39.

10. Иваненко В.А.,Иваненко В.С. Социальные права человека и социальные обязанности государства: международные и конституционные правовые аспекты.СПб.,2003. С.39.

11. Карташкин В.А.Гуманитарный компонент всеобъемлющей системы международной безопасности // Советский ежегодник международного права. 1987. М., 1988. С.28.

12. Крутько В.Н., Смирнова Т.М. Человеческий капитал: проблема и ресурс инновационного развития России. М., 2012.
13. Малый А.Ф. Конституционное право РФ: Учеб. пособ. в схемах. Саранск,1996. С.50.

14. Михайловская И. Б. Концепция прав человека и их значение для посткоммунистической России // Российский бюллетень по правам человека. 1997. № 9.C.2.

15. Мовчан А.П. Права человека и международные отношения. М.,1982. С. 61-64.

16. Островский Я.А. ООН и права человека. М.,1968. C. $78-85$;

17. Радько Т.Н. Функции социалистического права // Советское государство и право. 1977. N 5.

18. Сайнстейн К.Р. Против позитивных прав// Российский бюллетень по правам человека.1995.№6. С.19.

19. Ткаченко Ю.Г. Методологические вопросы теории права. М., 1980. С. 34.

20. Чиркин В.Е. Конституционное право зарубежных прав. М.,1997. С.59-61.

\section{References (transliteration):}

1. Abramov A.I. Ponyatie funktsii prava // Zhurnal rossiiskogo prava. 2006. N 2. S. 80.

2. Abramov A.I. Teoreticheskie i prakticheskie problemy realizatsii funktsii prava. Samara, 2008. S. 43.

3. Bakhin S. V. O klassifikatsii prav cheloveka, provozglashennykh v mezhdunarodnykh soglasheniyakh // Pravovedenie. 1991. №2.S.50.

4. Belyaeva L.A. Material'noe neravenstvo v Rossii. Real'nost' i tendentsii // Sotsiologicheskie issledovaniya. 2007. N 11. S. 34.

5. Gordon L.A. Sotsial'no-ekonomicheskie prava cheloveka: soderzhanie, osobennosti, znachenie dlya Rossii// Obshchestvennye nauki i sovremennost'.M.,1997. S.6.

6. Derkacheva T.V. Pravovoe regulirovanie gosudarstvennoi sotsial'noi pomoshchi (federal'nyi i regional'nyi aspekty): Dis. ... kand. yurid. nauk. M., 2002. S. 156-157.

7. Dobrynin N.M. Konstitutsionno-pravovye aspekty byudzhetnoi obespechennosti realizatsii sotsial'nykh garantii grazhdan v Rossiiskoi Federatsii i problema monetizatsii l'got // Pravo i politika. 2005. №11. S.4.

8. Eliseev B. P. Transformatsiya kontseptsii sotsial'nykh prav v Rossiiskoi Federatsii: obespechenie ekonomicheskoi reformy i soblyudenie konstitutsionno zakreplennykh sotsial'nykh prav // Yurist. 2004. №12. S. 7.

9. Zakharov M.L., Tuchkova E.G. Pravo sotsial'nogo obespecheniya Rossii: Uchebnik. 3-e izd. M., 2004. S. 39. 
DOI: 10.7256/1811-9018.2013.11.10037

При цитировании этой статьи сноска на dоі обязательна

Человек и государство

10. Ivanenko V.A.,Ivanenko V.S. Sotsial'nye prava cheloveka i sotsial'nye obyazannosti gosudarstva: mezhdunarodnye i konstitutsionnye pravovye aspekty.SPb., 2003. S.39.

11. Kartashkin V.A.Gumanitarnyi komponent vseob"emlyushchei sistemy mezhdunarodnoi bezopasnosti // Sovetskii ezhegodnik mezhdunarodnogo prava. 1987. M., 1988. S.28.

12. Krut'ko V.N., Smirnova T.M. Chelovecheskii kapital: problema i resurs innovatsionnogo razvitiya Rossii. M., 2012.

13. Malyi A.F. Konstitutsionnoe pravo RF: Ucheb. posob. v skhemakh. Saransk,1996. S.50.

14. Mikhailovskaya I. B. Kontseptsiya prav cheloveka i ikh znachenie dlya postkommunisticheskoi Rossii
// Rossiiskii byulleten' po pravam cheloveka. 1997. № 9.S.2.

15. Movchan A.P. Prava cheloveka i mezhdunarodnye otnosheniya. M.,1982. S. 61-64.

16. Ostrovskii Ya.A. OON i prava cheloveka. M.,1968. S. 78-85;

17. Rad'ko T.N. Funktsii sotsialisticheskogo prava // Sovetskoe gosudarstvo i pravo. 1977. N 5.

18. Sainstein K.R. Protiv pozitivnykh prav// Rossiiskii byulleten' po pravam cheloveka.1995.№6. S.19.

19. Tkachenko Yu.G. Metodologicheskie voprosy teorii prava. M., 1980. S. 34.

20. Chirkin V.E. Konstitutsionnoe pravo zarubezhnykh prav. M.,1997. S.59-61. 